\title{
Pengaruh Kegiatan Origami Kertas Washi Terhadap Kreativitas Anak Di Taman Kanak- Kanak Aisyiah No. 1 Muara Panas Kabupaten Solok
}

\author{
Mutiatul Husna \\ mutiatulhusna26@gmail.com
}

Rismareni Pransiska

\author{
Yulsyofriend
}

\begin{abstract}
This study aims to determine the relationship between parents' perceptions of the impact of smartphone on social development in children in the Cluster I Group of Kecamatan Nanggalo. Parents today are mostly negligent towards their child's growth and development and rarely stimulate their children with social developmental issues and physical energy depletion and stimulating thinking and working together are no longer attractive. Freedom and freedom to play children have been seized by smartphones. This research includes a type of correlation research with quantitative methods with a total population of 30 people found in Cluster 1 in Kecamatan Nanggalo. The sampling technique is saturated sampling. The instrument used is a questionnaire. The results showed that the significance of 0,000>0,05 and the coefficient of determination of the relationship of independent variables (parents' perception of the impact of smartphones) on the dependent variable (social development in children) was 55.3\%. It can be concluded that parents' perception of the impact of smartphones has a relationship to social development in children.
\end{abstract}

Keywords: Kertas Washi; Kreativitas

\section{PENDAHULUAN}

Pendidikan dibutuhkan setiap manusia dalam mengembangkan potensi yang ada pada dirinya, Oleh sebab itu pendidikan merupakan bagian yang tidak dapat dipisahkan dengan kehidupan manusia karena keduanya saling melengkapi. Salah satu bentuk pola pendidikan itu adalah penyelenggaraan pendidikan anak usia dini yang dilaksanakan dalam sebuah lembaga pendidikan Taman Kanak-kanak, karena pendidikan dari usia dini akan sangat berpengaruh kemasa mendatang. Menurut Undang-undang RI Nomor 20 Tahun 2003 tentang Sistem Pedidikan Nasional Pasal 1 ayat 14 menyatakan bahwa Pendidikan Anak Usia Dini adalah salah satu upaya i yang ditujukan kepada anak sejak lahir sampai dengan usia enam tahun yang dilakukan melalui pemberian rangsangan pendidikan untuk membantu pertumbuhan dan perkembangan jasmani dan rohani agar anak memiliki kesiapan dalam memasuki pendidikan lebih lanjut.

Satuan pendidikan anak usia dini pada jalur formal adalah Taman Kanak- kanak yang menyelengarakan pendidikan bagi anak usia 4 - 6 tahun yang di selenggarakan dengan tujuan untuk menfasilitasi pertumbuhan dan perkembangan anaka secara menyeluruh atau menekankan pada 
pengembangan seluruh aspek kepribadian anak. Pendidikan Taman Kanak-kanak perlu menyediakan berbagai kegiatan yang dapat mengembangkan berbagai aspek perkembangan anak, sehingga anak siap untuk memasuki pendidikan yang lebih lanjut. Tujuan pembelajaran di Taman Kanak-kanak adalah untuk meningkatkan potensi yang dimiliki oleh anak dan membuat anak terpacu untuk mengenal berbagai macam ilmu pengetahuan.

Aspek perkembangan pada anak meliputi aspek perkembangan kognitif, bahasa, sosial emosional, nilai agama dan moral, fisik motorik seni, dan kreativitas. Anak sebagai generasi penerus perlu dibekali kemampuan untuk mengoptimalkan seluruh aspek dan potensi yang dimiliki salah satunya ialah kreativitas. Kreativitas anak usia dini adalah kreativitas alamiah yang dibawa dari sejak lahir dan merupakan kemampuan untuk menghasilkan pemikiran-pemikiran yang asli, tidak biasa, dan sangat fleksibel dalam merespon dan mengembangkan pemikiran dan aktivitas. Kreativitas alami seorang anak usia dini terlihat dari rasa ingin tahunya. Hal ini terlihat banyaknya petanyaan yang diajukan kepada orang tuanya terhadap sesuatu yang dilihatnya. Adakalanya pertanyaan diulang-ulang dan tidak ada habis-habisnya. Selain itu, anak juga senang mencoba-coba alat mainannya sehingga tidak awet dan cepat rusak hanya karena rasa ingin tahu terhadap proses kejadiannya.

Dalam kehidupan ini kreativitas perlu dikembangkan sejak usia dini, karena kreativitas merupakan suatu kemampuan yang sangat berarti dalam proses kehidupan manusia. Kreativitas diperlukan untuk mengembangkan semua bakat dan kemampuan individu dalam pengembangan prestasi hidupnya, dengan kreativitas tinggi yang dimiliki seseorang, maka seseorang tersebut akan mempunyai pengembangan diri secara optimal.
Sudarma (2013:17) menyatakan
bahwa kreativitas adalah sebuah
keterampilan hidup (life skill) yang mampu melahirkan ide atau gagasan baru. Dalam menumbuhkan potensi kreatif anak usia dini diperlukan pendidikan dan lingkungan yang dapat memfasilitasi sifat alami anak dan menunjang tumbuhnya kreativitas. Lingkungan yang baik tentu saja akan menghasilkan suasana yang baik pula bagi kondisi manusia untuk belajar maupun bagi makhluk hidup lainnya untuk berkembang.(Amri \& Tharihk, 2018; Julianti, Nasirun, \& Wembrayarli, 2018; Khoirudin, 2019; KHOTIMAH, 2011; Prasasti, Mukono, \& Sudarmaji, 2005). Sifat-sifat alami inilah yang harus senantiasa di pupuk dan dikembangkan agar sifat kreatif mereka tidak hilang. Sifat alami anak usia dini itulah yang sangat menunjang tumbuhya kreativitas tersebut, antara lain pesona dan rasa takjub, imajinasi, rasa ingintahu, dan banyak bertanya. Melalui kreativitas, anak dapat berkreasi dengan sesuatu sesuai dengan bakat dan kemampuan yang dimilikinya. Selain itu, kreativitas juga mampu meningkatkan kualitas kehidupan anak dimasa mendatang.

Berdasarkan observasi awal yang dilakukan di Taman Kanak-kanak Aisyiah No. 1 Muara Panas Kabupaten Solok, peneliti menemukan kreativitas anak kurang berkembang secara optimal, hal ini terlihat dari kurang berkembangnya kreativitas pada anak. Anak kurang bisa membuat karya dengan idenya sendiri. Selain itu, anak juga kurang kreatif dalam memanfaatkan benda-benda di sekitarnya. Guru juga lebih sering mendikte anak tentang apa yang yang harus dibuat dan apa yang harus dilakukan anak. Sehingga, tidak muncul ide kreatif dari anak itu sendiri.

Penelitian ini dilakukan tidak terlepas dari penelitian-penelitian terdahulu, hasil penelitian yang mempertegas penelitian ini adalah penelitian dari Putri (2016) dengan 
judul "Pengaruh Kreasi Limbah Anorganik Terhadap Perkembangan Kreativitas Seni Anak di Taman Kanak-Kanak Negeri 1 Padang" menemukan bahwa pengaruh kreasi limbah anorganik di Taman KanakKanak Negeri 1 Padang terjadi perkembangan kreativitas seni anak. Penelitian ini relevan dengan penelitian yang peneliti lakukan, yaitu sama-sama bertujuan untuk mengembangkan aspek kreativitas anak, namun perbedaannya adalah penelitian terdahulu melalui kegiatan kreasi limbah anorganik sedangkan peneliti menggunakan kertas washi. Ningsih (2015) dengan judul "Pengaruh Penggunaan Kancing Baju Terhadap Perkembangan Kreativitas Anak di Taman Kanak-Kanak Kemala Bhayangkari 1 Padang". Penelitian ini menunjukkan bahwa melalui penggunaan kancing baju kreativitas anak akan meningkat. Penelitian ini relevan dengan penelitian yang peneliti lakukan, yaitu sama-sama bertujuan untuk mengembangkan aspek kreativitas anak, namun perbedaannya adalah penelitian terdahulu melalui kegiatan kancing baju sedangkan peneliti menggunakan kertas washi.

Adapun tujuan dari penelitian ini adalah untuk mengetahui pengaruh kegiatan origami kertas washi terhadap kreativitas anak di Taman Kanak-kanak Aisyiah no. 1 Muara Panas Kabupaten Solok.

\section{METODE PENELITIAN}

Berdasarkan permasalahan yang diteliti maka jenis penelitian ini adalah kuantitatif dengan dengan metode eksperimen dalam bentuk quasi experimental (eksperimen semu), Sugiyono (2014:72) mengemukakan metode eksperimen adalah metode penelitian yang digunakan untuk mencari pengaruh perlakuan tertentu terhadap yang lain dalam kondisi yang terkendalikan.

Populasi dalam penelitian ini adalah Taman Kanak-kanak Aisyiah no.1 Muara
Panas Kabupaten Solok memiliki jumlah anak sebanyak 60 orang, yang terbagi dalam 4 kelompok belajar, yaitu kelompok B1, B2, B3 dan B4. Adapun teknik pengambilan sampel yang dilakukan dalam penelitian ini adalah purposive sampling. Sampel dalam penelitian ini adalah kelompok belajar B2 dan B3, dimana kelompok B2 sebagai kelas eksperimen dan kelompok B3 sebagai kelompok kontrol. Adapun jumlah sampel untuk setiap kelompok adalah B2 sebanyak 10 orang anak, dan B3 sebanyak 10 orang anak.

Instrumen penelitian yang digunakan dalam penelitian ini adalah tes buatan guru. Tes dikatakan valid apabila tes itu dapat mengukur apa yang hendak diukur. Instrumen ini menggunakan Rating Scale untuk penilaiannya. Dengan kriteria penilaian yaitu Berkembang Sangat Baik diberi skor 4, Berkembang Sesuai Harapan 3, Mulai Berkembang 2, Belum Berkembang 1.

Data adalah kumpulan fakta, angka, atas segala sesuatu yang dapat dipercaya kebenarannya, sehingga dapat digunakan sebagai suatu kesimpulan. Jenis data dalam penelitian ini adalah data primer yaitu data yang langsung didapat dari data aslinya. Data tersebut adalah data nilai hasil test/observasi yang dilakukan peneliti. Sumber data adalah anak yang terpilih sebagai sampel penelitian B2 dan B3.

Adapun teknik analisis data yang digunakan dalam penelitian ini adalah membandingkan perbedaan dari dua ratarata nilai, sehingga dilakukan dengan uji t (ttest). Namun sebelumnya terlebih dahulu melakukan uji normalitas dengan uji liliefors, dan uji homogenitas dengan uji bartlett.

Untuk melakukan analisis perbedaan tersebut, perlu dilakukan uji normalitas. Menurut Syafril (2010:211). Uji normalitas digunakan untuk mengetahui apakah data yang akan diolah berasal dari data berdistribusi normal. Uji normalitas 
dilakukan sebelum mengolah data dengan teknik korelasi product moment, regresi, ttest dan anava dan sebagainya. Teknik yang sering digunakan untuk uji normalitas data adalah uji Liliefors.

Sebelum data diolah, agar diketahui suatu data berdistribusi normal atau tidak maka dilakukan uji Liliefors terlebih dahulu. Salah satu teknik yang sering digunakan untuk menguji homogenitas varians populasi adalah dengan menggunakan uji Bartlett. Jika sudah diketahui sebuah data berdistribusi normal dan bersifat homogen baru dilakukan analisis data sesuai dengan teknik analisis yang telah dilakukan yaitu dengan mencari perbandingan dengan menggunakan t- test. Menguji data yang telah diperoleh tersebut dengan rumus $t$ test.

\section{HASIL DAN PEMBAHASAN}

Hasil

Untuk menarik kesimpulan dari hasil penelitian, terlebih dahulu dilakukan uji hipotesis dengan menggunakan uji t. Sebelum melakukan uji $t$ terlebih dahulu dilakukan uji normalitas dan uji homogenitas terhadap hasil penelitian. Berdasarkan hasil penelitian anak yaitu kreativitas anak pada kelas eksperimen dan kelas kontrol, diperoleh hasil bahwa kreativitas anak di kelas eksperimen (kelompok B2) lebih tinggi dibandingkan pada kelas kontrol (kelompok B3). Berdasarkan uji normalitas kelompok eksperimen dan kelompok kontrol diperoleh harga Lo dan Lt pada taraf nyata 0,05 untuk $\mathrm{N}=10$ seperti tabel 1 berikut:

Tabel 1 Hasil Perhitungan Uji Liliefors Kelas Eksperimen dan Kelas Kontrol (pre-test)

\begin{tabular}{llrrrrr}
\hline No & Kelompok & N & A & L0 & Lt & $\begin{array}{c}\text { Keteran } \\
\text { gan }\end{array}$ \\
\hline 1 & Eksperimen & 10 & 0,05 & 0,2015 & 0,258 & Normal \\
\hline 2 & Kontrol & 10 & 0,05 & 0,2422 & 0,258 & Normal
\end{tabular}

Berdasarkan tabel 1 terlihat bahwa kelompok eksperimen nilai Lhitung 0,2015 lebih kecil dari Ltabel $\mathbf{0 , 2 5 8}$ untuk 0,05. Dengan demikian nilai kelompok eksperimen berasal dari data yang berdistribusi normal. Untuk kelompok kontrol diperoleh Lhitung 0, 2422 lebih kecil dari Ltabel $\mathbf{0 , 2 5 8}$ untuk 0,05. Ini berarti bahwa data kelompok kontrol berasal dari data yang berdistribusi normal.

Pengujian persyaratan yang kedua adalah pengujian homogenitas dengan menggunakan uji Barlett. Pengujian ini bertujuan untuk mengetahui apakah data berasal dari kelompok yang homogen, antara kelompok eksperimen dan kelompok kontrol. Jika chi kuadrat hitung <chi kuadrat tabel berarti data berasal dari kelompok yang homogen. Jika hasil perhitungan dari $x^{2}$ hitung lebih kecil dari $x^{2}$ tabel berarti bahwa data berasal dari kelompok yang homogen, sebaliknya jika $x^{2}$ hitung lebih besar dari pada $\mathrm{x}^{2}$ tabel maka kelompok tersebut tidak homogen.

Tabel 2. Hasil Uji Homogenitas pre-test Kelas Eksperimen dan kelas Kontrol

\begin{tabular}{ccccc}
\hline Kelas & $\mathrm{A}$ & $\chi^{2}$ & $\chi^{2}$ table & Kesimpulan \\
\hline $\begin{array}{c}\text { Eksperimen } \\
\text { Kontrol }\end{array}$ & 0,05 & 0,414 & 3,841 & Homogen \\
\hline
\end{tabular}

Dari Tabel 2 terlihat bahwa $\chi^{2}$ hitung kelompok eksperimen dan kelompok kontrol lebih kecil dari $\chi^{2}$ tabel $\left(\chi_{\text {hitung }}^{2} \chi^{2}\right.$ tabel), berarti kelompok eksperimen dan kelompok kontrol memiliki varians yang homogen. Setelah dilakukan uji normalitas dan uji homogenitas, diketahui bahwa kedua kelas sampel berdistribusi normal dan mempunyai varians homogen. Maka dapat dilanjutkan dengan pengujian hipotesis dengan menggunakan teknik t-tes.

- Jika $\boldsymbol{t}$ hitung $>\boldsymbol{t}$ tabel maka HO ditolak dan Ha diterima 
- Jika $\boldsymbol{t}$ hitung < t table maka HO diterima dan Ha ditolak

Melalui data pada tabel 3 akan digambarkan pengolahan data dengan ttest

\begin{tabular}{ccc}
$\begin{array}{c}\text { Tabel 3. Hasil Perhitungan Nilai Pre-test kelompok } \\
\text { eksperimen dan kelompok kontrol }\end{array}$ \\
\hline Aspek & $\begin{array}{c}\text { Kelompok } \\
\text { Eksperimen }\end{array}$ & $\begin{array}{c}\text { Kelompok } \\
\text { Kontrol }\end{array}$ \\
\hline $\mathrm{N}$ & 10 & 10 \\
\hline$X$ & 64,37 & 60 \\
\hline $\mathrm{SD}^{2}$ & 39,43 & 32,49
\end{tabular}

Pada $\mathrm{t}$ tabel untuk taraf nyata $\alpha=$ 0.05 (5\%) dengan df sebesar 18 adalah = 2, 10092 dengan demikian, dapat diketahui bahwa pada taraf nyata $\alpha=0.05(5 \%)$, thitung lebih kecil dari pada tabel $(\mathbf{1}, 549<2$, 10092 ). Jadi, dapat disimpulkan bahwa tidak terdapat perbedaan yang signifikan antara kemampuan kreativitas anak di kelas eksperimen dan kontrol dalam nilai pretest.

Tabel 4. Hasil Perhitungan Pre-test Pengujian dengan ttest

\begin{tabular}{ccccccc}
\hline & & & Hasil & \multicolumn{3}{c}{ ttabel } \\
No & $\begin{array}{c}\text { Kelom } \\
\text { pok }\end{array}$ & $\mathbf{N}$ & Rata-rata & Thitung & $\boldsymbol{\alpha} \mathbf{0 , 0 5}$ & $\begin{array}{c}\text { Keputu } \\
\text { san }\end{array}$ \\
\hline $\mathbf{1}$ & $\begin{array}{c}\text { Eksperi } \\
\text { men }\end{array}$ & 10 & 64,37 & & & $\begin{array}{c}\text { Terima } \\
\mathrm{H}_{0}\end{array}$ \\
\hline $\mathbf{2}$ & Kontrol & 10 & 60 & 1,549 & 2,10092 &
\end{tabular}

Pada t tabel untuk taraf nyata $\alpha=0,05$ ( $5 \%$ ) dengan df sebesar 18 adalah $=\mathbf{2}$, 10092. Dengan demikian, dapat diketahui bahwa pada taraf nyata $\alpha=0,05$ ( $5 \%$ ), thitunglebih kecil dari pada ttabel $(\mathbf{0 , 4 3 5 <}$
2, 10092 ). Jadi, dapat disimpulkan bahwa tidak terdapat perbedaan yang signifikan antara hasil pre-test (kemampuan awal) kreativitas anak di kelompok eksperimen dengan kelompok kontrol di Taman Kanakkanak Aisyiah no. 1 Muara Panas Kabupaten Solok.

Data post test penelitian kelas eksperimen dan kelas kontrol diolah untuk menentukan uji normalitas. Pada uji normalitas ini digunakan uji Liliefors seperti yang dikemukakan pada teknik analisis data. Analisis normalitas pada kelompok eksperimen dan kelompok kontrol.

Berdasarkan uji normalitas kelompok eksperimen dan kelompok kontrol diperoleh harga $L_{0}$ dan $L_{t}$ pada taraf nyata 0,05 untuk $N=10$ seperti pada tabel 5 berikut ini:

Tabel 5. Hasil Perhitungan Pengujian Liliefors Post-test Kelas Eksperimen dan Kelas Kontrol

\begin{tabular}{lcccccl}
\hline No & Kelompok & N & A & $\mathbf{L}_{\mathbf{0}}$ & $\mathbf{L}_{\mathbf{t}}$ & Keterangan \\
\hline 1 & Eksperimen & 10 & 0,05 & 0,1939 & 0,258 & Normal \\
\hline 2 & Kontrol & 10 & 0,05 & 0,1636 & 0,258 & Normal \\
\hline
\end{tabular}

Berdasarkan tabel 5 terlihat bahwa kelompok eksperimen nilai $L$ hitung 0, 1939 lebih kecil dari $L_{\text {tabel }} \mathbf{0 ,} 258$ untuk $\alpha=0,05$. Dengan demikian nilai kelompok eksperimen berasal dari data yang berdistribusi normal. Untuk kelompok kontrol diperoleh $L$ hitung $\mathbf{0 , 1 6 3 6}$ lebih kecil dari $L$ tabel $\mathbf{0 ,} 258$ untuk $\alpha=0,05$. Ini berarti bahwa data kelompok kontrol berasal dari data yang berdistribusi normal.

Pengujian persyaratan yang kedua adalah pengujian homogenitas dengan menggunakan uji Barlett. Pengujian ini bertujuan untuk mengetahui apakah data berasal dari kelompok yang homogen, antara kelompok eksperimen dan kelompok kontrol. Jika chi kuadrat hitung < chi kuadrat tabel berarti data berasal dari kelompok yang homogen. 
Tabel 6. Hasil Uji Homogenitas Post-test Kelas Eksperimen dan Kelas kontrol

\begin{tabular}{ccccc}
\hline Kelompok & A & $X^{2}$ Hitung & $X^{2}$ Tabel & Kesimpulan \\
\hline Eksperimen & 0,05 & 0,621 & 3,841 & Homogen \\
\hline Kontrol & & & &
\end{tabular}

Dari Tabel 6 terlihat bahwa $\chi^{2}$ hitung kelompok eksperimen dan kelompok kontrol lebih kecil dari $\chi_{\text {tabel }}^{2} \chi_{\text {hitung }}^{2}<\chi^{2}$ tabel), berarti kelompok eksperimen dan kelompok kontrol memiliki varians yang homogen.

Tabel 7. Hasil Perhitungan Nilai Post-test Kelas Eksperimen dan Kelas Kontrol

\begin{tabular}{lll}
\hline Aspek & $\begin{array}{c}\text { Kelompok } \\
\text { Eksperimen }\end{array}$ & $\begin{array}{l}\text { Kelompok } \\
\text { Kontrol }\end{array}$ \\
\hline $\mathrm{N}$ & 10 & 10 \\
\hline$X$ & 86,25 & 76,25 \\
\hline & 37,45 & 60,84
\end{tabular}

Pada $T$ tabel untuk taraf nyata $\alpha=0.05$ (5\%) dengan df sebesar 18 adalah $=2,10092$ dengan demikian, dapat diketahui bahwa pada taraf nyata $\chi^{2}=0,05(5 \%)$, thitung lebih besar dari pada $t_{\text {tabel }}(3,030>2,10092)$. Jadi, dapat disimpulkan bahwa terdapat perbedaan yang signifikan antara kreativitas anak di kelas eksperimen yang Menggunakan kegiatan origami kertas washi dengan kelas kontrol menggunakan media konvensional.

Tabel 8. Hasil Perhitungan Post-test Pengujian dengan ttest

\begin{tabular}{lccrcc}
\hline No Kelompok & $\mathbf{N}$ & $\begin{array}{c}\text { Hasil } \\
\text { Rata-rata }\end{array}$ & $\mathbf{t}_{\text {hitung }}$ & $\begin{array}{l}\mathbf{t}_{\text {table }} \\
\mathbf{\alpha ~ 0 , 0 5}\end{array}$ & $\begin{array}{l}\text { Keputu } \\
\text { san }\end{array}$ \\
\hline $\mathbf{1}$ Eksperimen & 10 & 86,25 & 3,030 & $\begin{array}{c}\text { Tolak } \\
2,190092 \\
\mathrm{H}_{0}\end{array}$ \\
\hline $\mathbf{2}$ Kontrol & 10 & 76,25 & &
\end{tabular}

Berdasarkan tabel 8 di atas dapat disimpulkan bahwa $\mathrm{H}_{a}$ diterima atau $\mathrm{H}_{0}$ ditolak yaitu terdapat perbedaan yang signifikan antara hasil post test (hasil akhir) kreativitas anak di kelas eksperimen yang diberikan treatment kertas washi dengan kreativitas anak di kelas kontrol yang diberikan treatment media konvensional. Dengan demikian, kelompok eksperimen memperoleh nilai yang lebih tinggi dibandingan kelompok kontrol. Hasil uji hipotesis yang didapat yaitu $t_{\text {hitung }}>t_{\text {tabel }}$ dimana 3,030> 2,10092 yang dibuktikan dengan taraf signifikan $\alpha 0,05$ ini berarti

Hipotesis $\mathrm{Ha}$ diterima dan $\mathrm{Ho}$ ditolak, dalam arti kata bahwa terdapat perbedaan yang signifikan antara hasil kreativitas anak kelompok eksperimen yang menggunakan kegiatan origami kertas washi dan kelompok kontrol menggunakan media konvensional di Taman Kanak-kanak Aisyiah no.1 Muara Panas Kab. Solok.. Dengan demikian dapat disimpulkan bahwa kegiatan origami kertas washi berpengaruh digunakan untuk kreativitas anak di Taman Kanak-kanak Aisyiah no. 1 Muara Panas Kabupaten Solok.

Setelah dilakukan perhitungan nilai pre-test dan post-test kelompok eksperimen dan kontrol maka selanjutnya akan dilakukan perbandingan antara nilai pre-test dan nilai post- test, yang tujuannya untuk melihat apakah ada perbedaan nilai post-test dan nilai pre-test anak.

Tabel 9. Perbandingan Hasil Perhitungan Nilai Pre-test dan Post-test

\begin{tabular}{ccccc}
\hline \multirow{2}{*}{ Variabel } & \multicolumn{2}{c}{ Pre-test } & \multicolumn{2}{c}{ Post-test } \\
\cline { 2 - 5 } & Eksperimen & Kontrol & Eksperimen & Kontrol \\
\hline $\begin{array}{c}\text { Nilai } \\
\text { tertinggi }\end{array}$ & 75 & 68,75 & 93,75 & 87,5 \\
\hline $\begin{array}{c}\text { Nilai } \\
\text { terendah }\end{array}$ & 56,25 & 50 & 75 & 62,5 \\
\hline $\begin{array}{c}\text { Rata- } \\
\text { rata }\end{array}$ & 64,37 & 60 & 86,25 & 76,25 \\
\hline
\end{tabular}

Perbandingan hasil perhitungan nilai pre-test dan nilai post-test.Pada pre-test nilai tertinggi yang diperoleh anak kelas eksperimen adalah 75 dan kelas kontrol 
adalah 68,75 dan nilai terendah di kelas eksperimen adalah 56,25 dan pada kelas kontrol nilai terendah adalah 50. Pada perhitungan rata-rata kelas eksperimen dan kontrol berbeda yaitu kelas eksperimen dengan rata-rata 64,37 sedangkan kontrol dengan rata-rata 60 . Pada post- test nilai tertinggi yang diperoleh anak kelas eksperimen yaitu 93,75 dan nilai terendah 75 dengan rata-rata 86,25 sedangkan pada kelas kontrol post-test nilai tertinggi yang diperoleh anak yaitu 87,5 dan nilai terendah 62,5 dengan rata-rata 76,25.

Perbandingan hasil perhitungan nilai pre-test dan post test terlihat pada nilai tertinggi dan nilai terendah yang diperoleh anak dan terlihat pada rata-rata kelas eksperimen dan kelas kontrol pada posttest dimana pada post-test rata-rata menjadi lebih meningkat dari rata-rata pretest setelah dilakukan treatment. Untuk lebih jelas bisa dilihat pada grafik pada gambar 1.

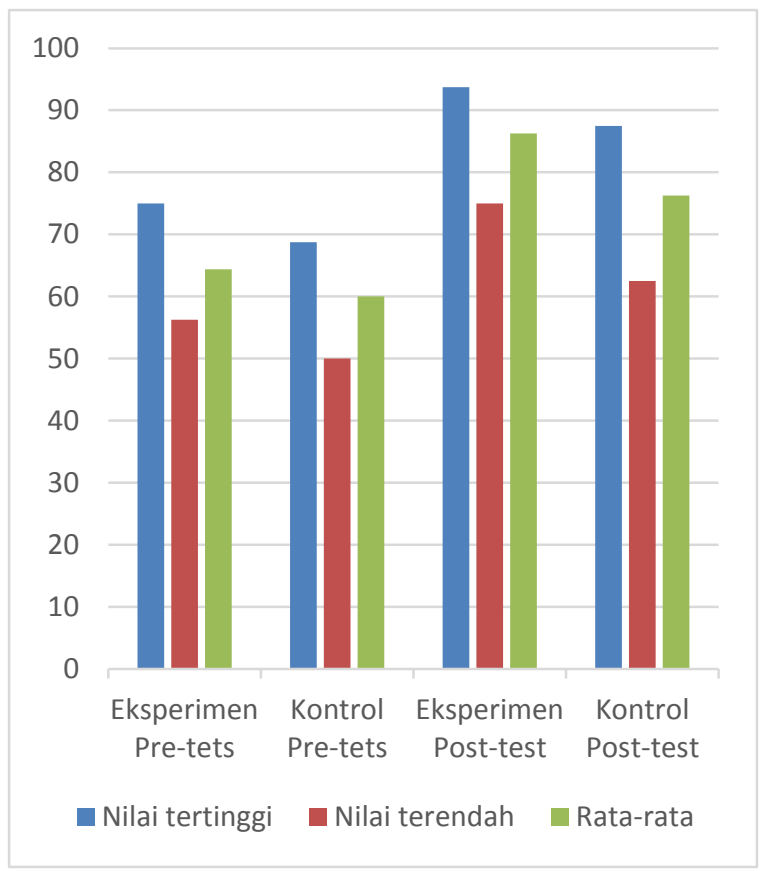

Gambar 1. Data Perbandingan Hasil Pre-Test dan PostTest Kreativitas Anak Kelompok Eksperimen dan Kelompok Kontrol

Berdasarkan Grafik 1 di atas dapat disimpulkan bahwa kegiatan origami kertas washi berpengaruh dalam kreativitas anak dibandingkan kelas kontrol mnggunakan media konvensional.

\section{Pembahasan}

Berdasarkan hasil pre-test kreativitas anak pada kelompok eksperimen dan kelompok kontrol pada pre-test diperoleh angka rata-rata kelompok eksperimen yaitu 64,37. Angka rata-rata kelompok kontrol yaitu 60. Berdasarkan hasil analisis data yang telah dilakukan bahwa thitungsebesar 1,549 dibandingkan dengan $\alpha=0.05$ ( $t_{\text {tabel }}=$ 2,10092) dengan derajat kebebasan $\mathrm{dk}$ $\left(N_{1}-1\right)+\left(N_{2}-1\right)=18$. Dengan demikian $t_{\text {hitung }}<t_{\text {tabel }}$ yaitu $1,549<2,10092$, maka dapat dikatakan bahwa hipotesis $\mathrm{H}_{\mathrm{a}}$ ditolak $\mathrm{H}_{0}$ diterima. Jadi, dapat disimpulkan bahwa tidak terdapat perbedaan yang signifikan antara hasil kreatifitas anak dikelas eksperimen yang menggunakan kegiatan origami kertas washi dengan kelas kontrol yang menggunakan media konvensional. Dapat disimpulkan bahwa tidak terdapat perbedaan yang signifikan.

Hasil Perkembangan kreativitas anak pada kelompok eksperimen dan kelompok kontrol pada post-test diperoleh angka rata-rata kelompok eksperimen yaitu 86,25 dan nilai rata-rata kelas kontrol 76,25. Berdasarkan hasil analisis data yang telah dilakukan bahwa thitung sebesar 3,030 dibandingkan dengan $\alpha=0,05$ ( $t_{\text {tabel }}=$ $2,10092)$ dengan derajat kebebasan $\mathrm{dk}\left(\mathrm{N}_{1}{ }^{-}\right.$ $1)+\left(N_{2}-1\right)=18$. Dengan demikian $t_{\text {hitung }}>t_{\text {tabel }}$ yaitu 3,030>2,10092 maka dapat dikatakan bahwa hipotesis $\mathrm{H}_{0}$ ditolak dan $\mathrm{H}_{\mathrm{a}}$ diterima. Dari hasil tersebut terlihat perbedaan yang signifikan antara hasil kreativitas anak di kelas eksperimen yang menggunakan kegiatan origami kertas washi dengan kelas kontrol yang menggunakan media konvensional. Jadi, dapat disimpulkan bahwa terdapat pengaruh yang signifikan dari penggunaan kegiatan origami kertas washi terhadap kreativitas anak di Taman Kanak-kanak Aisyiah no.1 Muara Panas Kabupaten Solok. 
Menurut Sumanto (2005:99-100) Melipat atau Origami adalah suatu teknik berkarya seni atau kerajinan tangan yang umumnya dibuat dari bahan kertas, dengan tujuan untuk menghasilkan aneka bentuk mainan, hiasan, benda fungsional, alat peraga, dan kreasi lainnya. Bagi anak usia taman kanak-kanak melipat merupakan salah satu bentuk kegiatan bermain kreatif yang menarik dan menyenangkan. Melalui kegiatan ini dapat mengembangkan kompetensi fikir, imajinasi, rasa seni, dan keteranpilan anak. Melipat dilakukan dengan cara mengubah lembaran kertas berbentuk bujur sangkar, empat persegi, atau segi tiga menurut arah atau pola lipatan tertentu secara bertahap sampai dihasilkan suatu model atau bentuk lipatan yang diinginkan. Adapun kreativitas melipat yang dimaksudkan disini adalah kegiatan berlatih membuat suatu bentuk/model lipatan yang hasilnya bisa dijadikan hiasan dinding dan hiasan gantung dengan ditambahkan tali/ benang serta juga bisa digunakan untuk mainan.

Anak kelompok eksperimen (kelas B2) dalam mengikuti kegiatan washi sangat senang karena dapat belajar membuat boneka sendiri. Kegiatan washi juga dapat melatih konsentrasi dan ingatan anak karena pada kegiatan washi anak TK kelompok eksperimen (B2) masih meniru sesuai perintah guru. Washi melatih kesabaran anak, di mana kegiatan washi memang cukup rumit dilakukan, sehingga untuk mencapai hasil yang sesuai bentuk yang diinginkan membutuhkan kesabaran. Melatih ketelitian anak, dalam kegiatan washi melatih anak kelompok eksperimen (B2) untuk teliti artinya apakah lipatannya sudah lurus atau belum. Melatih kerapian, melipat kertas dengan hasil rapi akan terlihat indah bentuk lipatannya. Hal ini sependapat dengan Sumanto (2006:100) yang menyatakan bahwa tujuan kegiatan melipat kertas adalah untuk melatih daya ingat, pengamatan, keterampilan tangan, mengembangkan daya fantasi, kreasi, ketelitian, kerapian, dan perasaan keindahan.

Pada saat peneliti melakukan penelitian menggunakan kegiatan origami kertas washi pada kelompok eksperimen (kelas B2) di Taman Kanak-kanak Aisyiah No.1 Muara Panas Kabupaten Solok, Semua anak terlihat antusias dan semangat untuk membuat kegiatan origami boneka washi ini. Karena pembelajaran yang diberikan menarik dan baru bagi anak, hasil karyanya pun terlihat lebih nyata, melalui kegiatan origamai kertas washi ini anak mampu mengembangkan kreativitasnya.

Sedangkan kontrol menggunakan media konvensional dalam kreativitas anak. Sebagian anak kurang antusias untuk melakukan kegiatan. Hal ini disebabkan karena media konvensional memiliki tekstur yang lebih halus dan tidak memiliki corak sehingga anak tidak bersemangat dalam melakukan kegiatan, hasilnyapun tidak menarik bagi anak. Hal ini menyebabkan hanya sebagian anak yang berkembang kreativitasnya.

Jadi, hasil kreativitas anak di kelompok eksperimen lebih baik dari pada kreativitas anak di kelas kontrol. Dapat dilihat dari kelas eksperimen menggunakan kegiatan origami kertas washi lebih menarik bgi anak karena hasil karyanya lebih terlihat nyata, sedangkan dikelas kontrol yang menggunakan media konvensional kurang menarik bagi anak. Karena media konvensional memiliki tekstur yang lebih halus dan tidak memiliki corak dan tidak menarik bagi anak. Hal ini dapat dilihat dari nilai rata-rata anak kelas eksperimen yang lebih tinggi daripada kelas kontrol. Kegiatan origami ini juga bisa membuat anak-anak menjadi lebih kreatif karena menggunakan imajinasinya untuk membentuk sesuatu. Pemberian aktifitas atau interfensi aktifitas semacam ini sejalan dengan penelitian yang dilakukan oleh (Agustriana, 2019; Alidawati, 2019; Juita, 2019; Julaila, 2019; Kusumah \& 
Munandar, 2017; Walid, Putra, \& Asiyah, 2019; Wati, Saparahayuningsih, \& Yulidesni, 2017) yang memiliki hasil bahwa pemberian aktifitas akademik yang merangsang daya imajinasi siswa akan meningkatkan atau daya imajinasi melalui hasil kognitif. Maka dapat disimpulkan bahwa penggunaan kegiatan origami kertas washi efektif mengembangkan kreativitas pada anak.

\section{KESIMPULAN}

Berdasarkan hasil penelitian dan pembahasan yang telah dikemukakan pada bab terdahulu, maka pada bagian ini akan dikemukakan beberapa simpulan terhadap hasil penelitian. Hasil penelitian yang diperoleh terdapat perbedaan hasil kreativitas anak di Taman Kanak-kanak Aisyiah No.1 Muara Panas Kabupaten Solok, yang signifikan yaitu antara kelas eksperimen (B2) dan kelas kontrol (B3). Hal ini membuktikan bahwa dengan kegiatan origami kertas washi berpengaruh digunakan terhadap kreativitas anak, sehingga nilai rata-rata yang diperoleh dari kelas eksperimen lebih tinggi $(86,25)$ dibandingkan kelas kontrol $(76,25)$. Dari hasil uji hipotesis didapat thitung $>$ ttabel dimana 3,030>2,10092 yang dibuktikan dengan taraf signifikan $\alpha 0,05$ ini berarti terdapat perbedaan yang signifikan antara hasil kreativitas anak di kelas eksperimen yang menggunakan kegiatan origami kertas washi dengan kelas kontrol yang menggunakan media konvensional. Dengan demikian, kegiatan origami kertas washi terbukti memberikan pengaruh yang signifikan dalam mengembangan kreativitas anak di Taman Kanak-kanak Aisyiah No.1 Muara Panas Kabupaten Solok.

Saran

Bagi anak diharapkan agar kreativitas anak dapat berkembang dengan baik melalui kegiatan origami kertas washi. Bagi guru dalam mengembangkan kreativitas anak hendaknya guru merancang kegiatan dan menggunakan media yang bervariasi kepada anak. sehinggga kegiatan pembelajaran lebih menarik dan kreativitas anak dapat berkembang dengan baik. Salah satu kegiatan pembelajaran yang dapat digunakan adalah penggunaan kegiatan origami kertas washi. Bagi Kepala Taman Kanak-kanak diharapkan agar lebih memberikan motivasi yang lebih menunjang pembelajaran di sekolah untuk mengembangkan berbagai aspek perkembangan anak serta kreativitas pada anak khususnya kreativitas anak. Bagi Peneliti Selanjutnya hasil penelitian ini dapat menjadi sumber bacaan/literature bagi peneliti lain untuk mengembangkan penelitian yang lama.

\section{DAFTAR PUSTAKA}

Agustriana, N. (2019). PENGARUH METODE EDUTAINMENT DAN IDENTITAS DIRI TERHADAP KETERAMPILAN SOSIAL ANAK. Al-Fitrah, 1(2), 216-228. Retrieved from

http://ejournal.iainbengkulu.ac.id/index .php/alfitrah/article/view/1517

Alidawati, A. (2019). Meningkatkan Hasil Belajar Siswa Dengan Menggunakan Media Gambar Berupa Rumah Adat Tentang Keragaman Budaya Di Indonesia Pada Pelajaran IPS Di Kelas V SD Negeri 03 Kota Mukomuko. Indonesian Journal of Social Science Education (IJSSE), 1(1), 78-84. Retrieved from http://ejournal.iainbengkulu.ac.id/index .php/ijsse/article/view/1686/1440

Amri, A., \& Tharihk, A. J. (2018). PENGEMBANGAN PERANGKAT ASESMEN PEMBELAJARAN PROYEK PADA MATERI PENCEMARAN DAN KERUSAKAN LINGKUNGAN. DIDAKTIKA BIOLOGI: Jurnal Penelitian Pendidikan Biologi, 2(2), 103-112. https://doi.org/10.32502/DIKBIO.V2I2 .1283 
Indah. (2010). Kreasi Boneka Dari Kertas Washi. Jakarta: Kawan Pustaka

Juita, R. (2019). Meningkatkan Hasil Belajar IPA Melalui Metode Eksperimen Pada Siswa Kelas IV SDN 02 Kota Mukomuko. IJIS Edu: Indonesian Journal of Integrated Science Education, 1(1), 43-50. Retrieved from http://ejournal.iainbengkulu.ac.id/index .php/ijisedu

Julaila. (2019). Upaya Meningkatkan Hasil Belajar IPA Siswa Kelas IV SDN 01 Mukomuko Menggunakan Media Torso. IJIS Edu : Indonesian Journal of Integrated Science Education, 1(1), 51-62. Retrieved from http://ejournal.iainbengkulu.ac.id/index .php/ijisedu

Julianti, R., Nasirun, M., \& Wembrayarli, W. (2018). PELAKSANAAN PERILAKU HIDUP BERSIH DAN SEHAT (PHBS) DI LINGKUNGAN SEKOLAH. Jurnal Ilmiah POTENSIA, 3(2). Retrieved from https://ejournal.unib.ac.id/index.php/po tensia/article/view/2960/pdf

Khoirudin, M. (2019). Pengembangan Modul Pembelajaran IPA Biologi Berbasis Scientific Approach Terintegrasi Nilai Keislaman Pada Materi Interaksi Antar Makhluk Hidup Dengan Lingkungan. IJIS Edu: Indonesian Journal of Integrated Science Education, 1(1), 33-42. Retrieved from http://ejournal.iainbengkulu.ac.id/index .php/ijisedu

KHOTIMAH, D. R. K. (2011). HUBUNGAN FAKTOR LINGKUNGAN FISIK RUMAH DAN SUMBER PENCEMARAN DALAM RUMAH DENGAN KEJADIAN ISPA PADA BALITA DI DESA
BANGETAYU

WETAN

KECAMATAN GENUK KOTA SEMARANG. Semarang: Diponegoro University. Retrieved from http://eprints.undip.ac.id/33244/

Kusumah, R. G. T., \& Munandar, A. (2017). ANALYSIS OF THE RELATIONSHIP BETWEEN SELF EFFICACY AND HEALTHY LIVING CONCIOUSNESS TOWARD SCIENCE LEARNING OUTCOME. EDUSAINS, 9(2), 132-138. https://doi.org/10.15408/ES.V9I2.2183

Prasasti, C. I., Mukono, J., \& Sudarmaji, S. (2005). Pengaruh kualitas udara dalam ruangan ber-AC terhadap gangguan kesehatan. Jurnal Kesehatan Lingkungan, 1(2).

Sudarma. (2014). Pendidikan Anak Usia Dini Berkarakter. Yogyakarta: Perpustakaan Nasional RI

Sugiyono (2014). Metode Penelitian Kantitatif, Kualitatif dan $R \& D$. Bandung: Alfabeta.

Sumanto. (2006). Pengembangan Kreativitas Seni Rupa Anak SD. Jakarta: Departemen Pendidikan Nasional Direktorat Jenderal Pendidikan Tinggi, Direktorat Pendidikan Tenaga Kependidikan dan Ketenagaan Perguruan Tinggi.

Suryana, D. (2016). Pendidikan Anak Usia Dini Stimulasi \& Aspek Perkembangan Anak. Jakarta: Kencana.

Syafril. 2010. Statistika. Padang: Sukabina Press.

Undang-Undang No 20 tahun 2003 tentang Sistem Pendidikan Nasiona

Walid, A., Putra, E. P., \& Asiyah. (2019). Pembelajaran Biologi Menggunakan Problem Solving Disertai Diagram 
Tree Untuk Memberdayakan

Kemampuan Berpikir Logis Dan

Kemampuan Menafsirkan Siswa. IJIS

Edu : Indonesian Journal of Integrated

Science Education, 1(1), 1-6.

Retrieved from

http://ejournal.iainbengkulu.ac.id/index

.php/ijisedu

Wati, K. I., Saparahayuningsih, S., \& Yulidesni, Y. (2017). Meningkatan Keterampilan Motorik Halus Anak Melalui Kegiatan Pembelajaran Membatik Menggunakan Media Tepung Pada Anak Kelompok B PAUD Aisyiyah III Kota Bengkulu. Jurnal Ilmiah POTENSIA, 2(2), 91-94. https://doi.org/10.33369/jip.2.2 